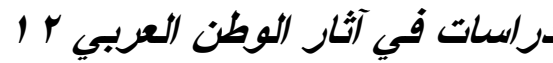

\title{
IDENTIFICATION AND CHARACTERIZATION OF FIBERS AND WEAVE STRUCTURES OF THREE ARCHAEOLOGICAL TEXTILES FRAGMENTS, FROM SOHAG EXCAVATIONS, EGYPT
}

'D. Mohamed Marouf

\begin{abstract}
Three archaeological textiles fragments from different excavations in Sohag were investigated by means of Stereo Microscopy (SM), Scanning Electron Microscopy (SEM). Three textile fragments were found out in three different sites; White Monastery 'Deir elabiad' in west of Nile river (12km) (fourth century A.D), temple of Ramses II (1290- 1224 BC) in Akhmeem city (10km east of Nile river) and Osireion's temple in Abydos (5000 B.C.) western-south of Nile river $(11 \mathrm{~km})$.Much information has been obtained relating identification kind of the natural fibers and their characteristic features and the determination of the kind of weave structure techniques used. In addition to, study of torsion of the spun yarns, wool fibers were recognized in three fragments. Plain weave technique together with derived weaves such as reps, whether regular or irregular warp reps was identified. Three textile Fragments have also been found in various states of degradation because the fibers were extremely brittle, indicating some degradation of the material. This article presents important results and conclusions which may help understand origin and technology of archaeological textiles (type of spinning and weave).
\end{abstract}

Keywords: Scanning electron microscope (SEM), natural fibers, plain weave, regular and irregular warps reps, torsion direction, Stereo microscopy (SM) and archaeological textiles

'Correspondence: Mohamed Marouf, an associate professor in Conservation Dept. Faculty of Arts, Sohag University, Egypt. 


\section{Introduction}

Three archaeological textiles fragments were found out in three different excavations in Sohag. These excavations were carried out in the white monastery 'Deir el-abiad', Abydos and Akhmeem) in 1998, 2001 and 2008. The main objective of this study on textiles found in Sohag's excavations is to identify the type of natural fibers; weave structures and orientation's torsion of the threads, the study also relates information to the archaeological questions surrounding the history of these objects and technique of their manufacture. Information of fiber type is very important since some previous studies suggest that wool fiber was not used in archaeological textiles in ancient Egyptian ages (pharoahnic period), but it was known in Byzantine period in Egypt (284-641 AD) ${ }^{1}$. Information on these textiles will also allow conclusions on the type of the dominant weave structures in this time. The classical approach to analyze textiles is via stereo microscope (SM). Stereo microscopy readily reveals the weave structure and handedness of spun yarns. The shape of fibers allows for the discrimination between warp's and weft's fibers in three textile fragments, in addition to discrimination between directions of twist of spun yarns. The next step is a shape investigation in more details using scanning electron microscopy (SEM) images.

The microscopic techniques mentioned above were applied to textile samples from the Sohag's excavations identifying wool fibers whether in warp or weft threads, therefore the characteristic features relating the wool fibers were identified by scanning electron microscopy (SEM) such as remains of scales as a characteristic morphological structure of wool fiber in the longitudinal fiber section. On the other hand, Plain weave with its derived weaves such as warp reps whether regular or irregular warp

\footnotetext{
${ }^{1}$ Abdul-hamid, R. and Mohamed, T. (2001); "Egypt in the Byzantine period 284-641 AD" Arab Egypt house for publishing, Cairo.http://www.mediafire.com/?ezhciyd0mny\#2 Nov., 7, 2010
} 
reps were identified in three fragments. Moreover, twist direction of the spun yarns in three objects was identified whether in $(S)$ or $(Z)$ torsion both of warp and weft threads.

\section{Methodology}

\subsection{Description of three textile fragments}

Ancient textile fragments were found out at different three sites in Sohag the first fragment was found out in west of white Monastery 'Deir el-abiad' (the $4^{\text {th }}$ century) in west of Sohag and the second fragment was found out in the southern excavation of temple of Ramses II (1290-1224 B.C) in Akhmeem city east of the Nile River, while the third fragment was found out in north of Osireion's temple in Abydos (5000 B.C.) western-south of Sohag (11km west of the Nile river) Fig. 1

Three textile fragments were investigated and reported relating technical analysis and specification of the fragments in table 1 that demonstrates the type of natural fibers, the type of spinning and weave structures, as well as account of warp/weft threads in $1 \mathrm{~cm}^{2}$ and ply yarn in warp/weft threads.

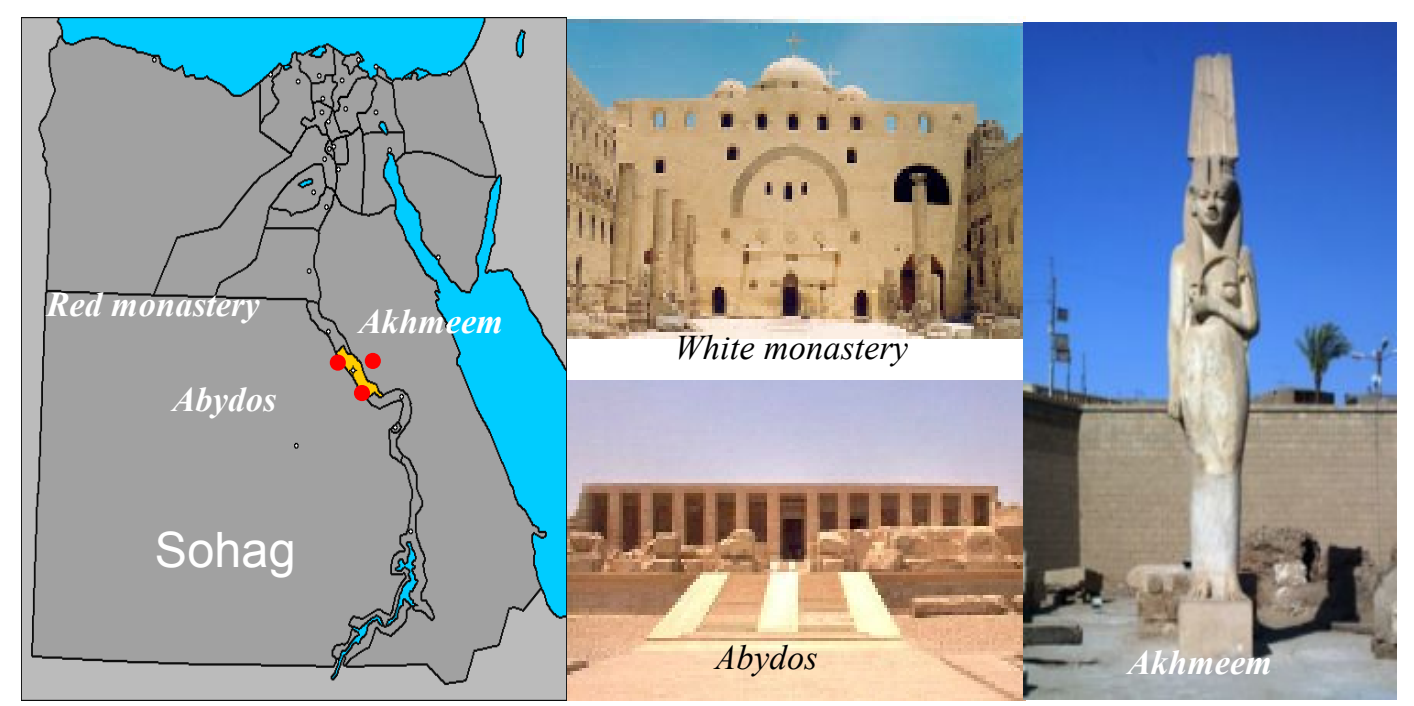

Fig. 1 three archaeological sites in Sohag where the ancient textile fragments were found out 
Table 1 technical analysis and specification of three textile fragments

\begin{tabular}{|c|c|c|c|}
\hline \multirow[b]{2}{*}{ Items } & \multicolumn{3}{|c|}{ Descriptions of fragments } \\
\hline & 1 & 2 & 3 \\
\hline Measure & $21 \times 14.1 \mathrm{~cm}$ & $12.2 \times 11.4 \mathrm{~cm}$ & $26 \times 9.8 \mathrm{~cm}$ \\
\hline Warp threads & 8 yarns & 6 yarns & 9 yarns \\
\hline Weft threads & 30 yarns & 7 yarns & 12 yarns \\
\hline $\begin{array}{l}\text { Fiber materials } \\
\text { (warp/weft) }\end{array}$ & Wool & Wool & Wool \\
\hline $\begin{array}{l}\text { Diameter of fiber } \\
\text { (warp/Weft) }\end{array}$ & $18-20 / 16-18 \mu \mathrm{m}$ & $23-25 / 20-22 \mu \mathrm{m}$ & $20-22 / 18-23 \mu \mathrm{m}$ \\
\hline Colors & $\begin{array}{l}\text { Red, green and dark } \\
\text { blue }\end{array}$ & $\begin{array}{l}\text { Red and traces } \\
\text { from dark violet }\end{array}$ & $\begin{array}{l}\text { Yellow and brick } \\
\text { red }\end{array}$ \\
\hline Spinning yarn & $(\mathrm{S})$ torsion & $(\mathrm{S}) \&(\mathrm{Z})$ torsion & $(\mathrm{S})$ torsion \\
\hline Ply yarn (warp) & 3ply yarn & 2 ply yarn & 2ply yarn \\
\hline Ply yarn (weft) & 1 ply yarn & 1 ply yarn & 1 ply yarn \\
\hline Weave structure & $\begin{array}{l}\mathrm{PW}^{*} 1 / 1 \text { and } \mathrm{IWR}^{* *} \\
2 / 1\end{array}$ & $\begin{array}{l}\mathrm{RWR}^{* * *} 2 / 2 \text { and } \\
\operatorname{IWR} 2 / 3\end{array}$ & $\begin{array}{l}\text { PW } 1 / 1 \text { and } \\
\text { RWR2/2 }\end{array}$ \\
\hline Ornaments & Horizontal ribbons & Without & Without \\
\hline
\end{tabular}

\subsection{Investigation methods and techniques}

The stiffened samples were investigated with a stereo microscope (Bausch\& Lomb) and then covered with an $18 \mathrm{~nm}$ layer of an AuPd alloy to allow observation by a scanning electron microscope (SEM) JEOL model JSM 5300. The morphological analysis carried out with these microscope techniques allowed us to detect for each sample its microscopic features peculiar to the natural fiber components and thus identify them. The thread's torsion's direction set by the spinning process, the manner in which the warp (parallel threads) and the weft (threads perpendicular to the weave) had been interwoven (weave) and the minimum number of threads and weave necessary to obtain the weave (weave ratio) for each sample, were determined by using microscopy techniques. The weave graphical pattern is made on graph paper and it is assumed that the spaces between the vertical and the horizontal lines represent, respectively, the yarns of warp and weft; moreover, the squared spaces formed by the weave of weft and warp are filled in when the yarn passes over the weft. 

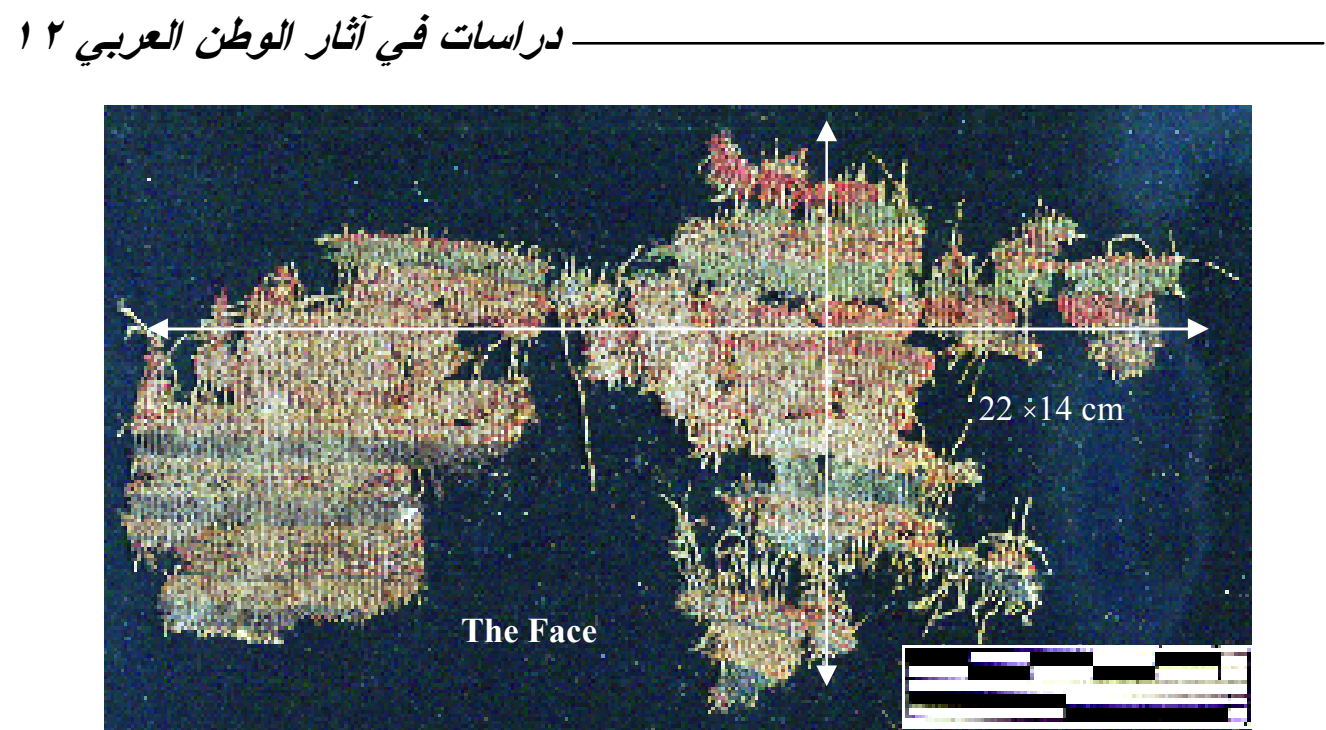

Fig. 2 three textile fragments: (a) the1st fragment that found out at white monastery in Sohag. $(22.0 \times 14.0 \mathrm{~cm})$

\section{Results}

\subsection{Morphological analysis}

Figure 3 shows the photographs of the samples which were investigated by using (SEM), these samples represent warp and weft threads, a longitudinal observation showed that the fibers are wool fibers, since the microscopic examination illustrates that the presence of a scaly layer is the distinguishing feature of wool fiber. The scales are arranged very closely on the fiber surface in a single layer. So that the edges of separate scales partially cover the adjacent ones. ${ }^{2}$ Their upper parts protruding on the fiber surface have their ends always directed to the top part of the hair. In this layer the scales overlap each other like shingles on a roof, which imparts to it the features of a protection sheath. As the name implies, the scales form an irregular network over the surface of the fiber.

\footnotetext{
${ }^{2}$ Sadov, F., et al; (1970) "Chemical technology of fibrous materials" MIR publishers, Moscow, p. 78
} 

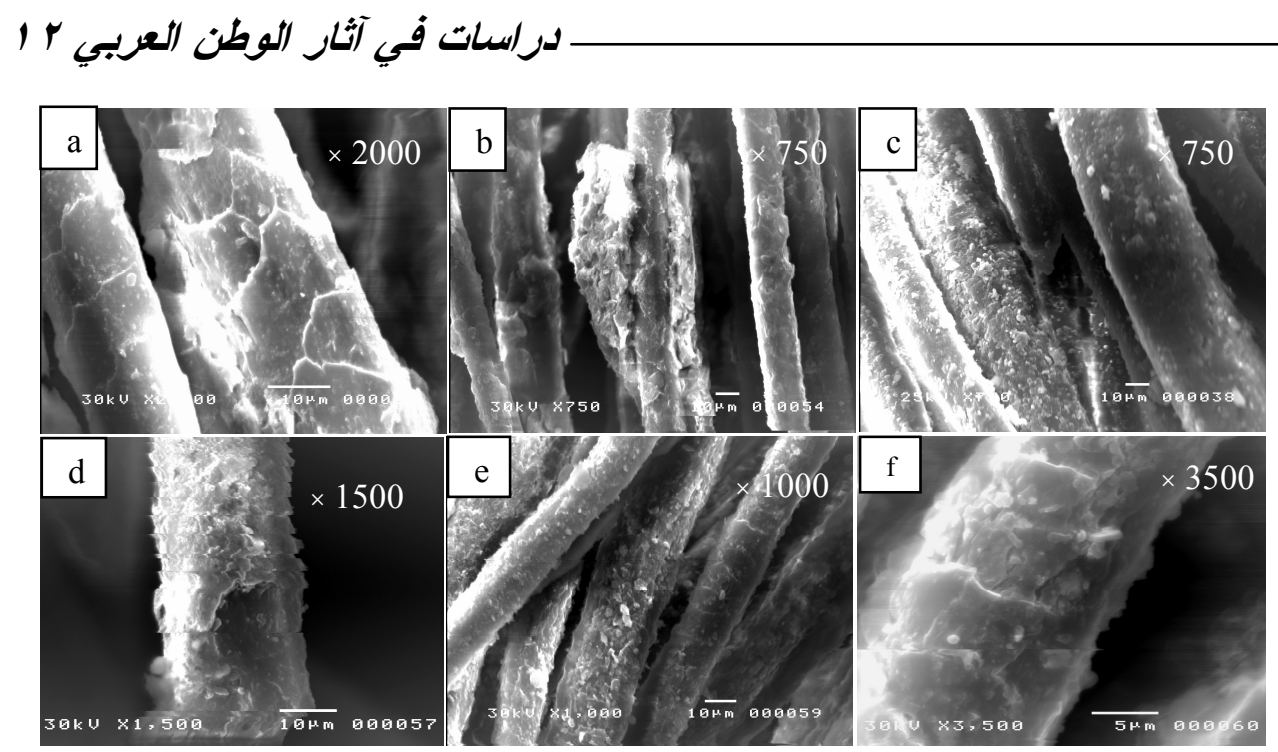

Fig. 3 SEM micrographs show the morphological structure of the wool fibers which represent warp and weft threads. $(a, b)$ samples of the $1^{\text {st }}$. fragment, $(c, d)$ of the $2^{\text {nd }}$.

Fragment and $(\mathrm{e}, \mathrm{f})$ of the $3^{\text {rd }}$. fragment

Another characteristic feature of the scale cells is the form of their margin. The scale pattern is a useful tool for distinguishing certain fiber types (e.g. fine wool and cashmere, medium wool and mohair). In addition to the scale pattern, the visible scale length, i.e. the distance between serration along the fiber axis, is a useful, but by no means infallible, aid to fiber identification. ${ }^{3}$ So when the photographs of the wool fibers were investigated we found that scale length in wool fiber of the second fragment (warp threads) is 16-18 $\mu \mathrm{m}$, while lengths of scales of wool fiber in the weft threads are 14-16 $\mu \mathrm{m}$. Also the wool fiber in the $1^{\text {st }}$. fragment (warp threads) is $8-10 \mu \mathrm{m}$ while in weft threads are $5-8 \mu \mathrm{m}$, fig. 4 . In this context, the fiber diameters of wool fibers were assessed by

\footnotetext{
${ }^{3}$ Menkart, J. and Bray, R. (1962)'Wool Handbook-The morphology and physical properties of wool', the $3^{\text {rd }}$ edition, Vol. I, London, p. 154-156
} 


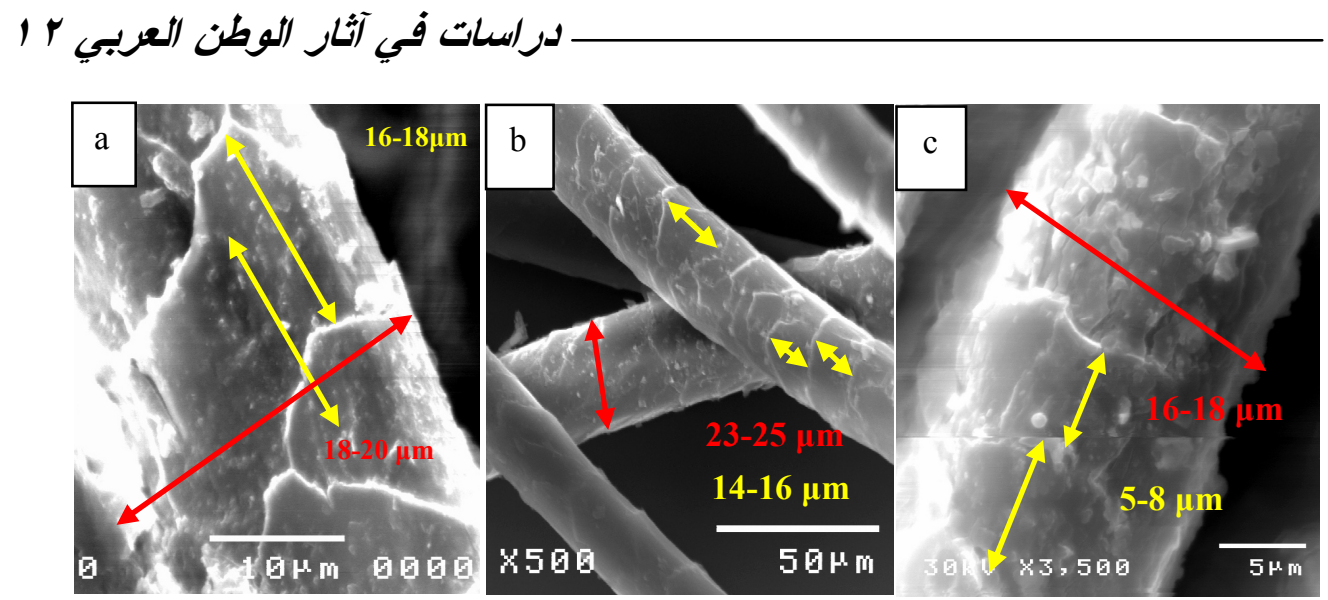

Fig. 4 SEM micrographs show scales length and diameter of wool fibers of the textile objects; the $1^{\text {st }}$ and $2^{\text {nd }}$ fragments

using scanning electron micrographs ${ }^{4}$. The averages of wool fibers for each fragment range in mean diameter from 16-20 $\mu \mathrm{m}$, fig. 4.

\subsection{Technical analyses}

\subsubsection{The first textile fragment}

Figures 5 and 6 show microscopic photographs and micrographs of one of the most important parts in this fragment and illustrate three techniques of weave structures are normal plain weave $1 / 1$; overlapped plain weave $1 / 1$ and irregular warp reps weave $2 / 1$. The plain weave technique is considered the simplest of all patterns. The warp and the weft are crossed over each other one by one alternately up and down and they are interlaced. ${ }^{5}$ While irregular warp reps $2 / 1$ was made in $0.5 \mathrm{~cm}$, fig. 5 (c) among two regions were woven with overlapped plain weave $1 / 1(2.0 \mathrm{~mm})$, fig. 5 (a)

\footnotetext{
${ }^{4}$ Müller, M. et al; (2004) " Identification of ancient textile fibers from Khirbet Qumran caves using synchrotron radiation microbeam diffraction" SPECTROCHIMICA ACTA, Part B, 59, Www.elsevier.com/locate/sab pp: 1669-1671

${ }^{5}$ Nakamura, A. ; (2000), " Fiber science and technology" Science publishers, Inc., USA, p.154 .
} 


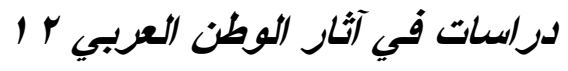

(3) Normal plain weave $1 / 1$

(2) Overlapped plain weave $1 / 1$

(1) Irregular warp reps weave $2 / 1$

(2) Overlapped plain weave $1 / 1$

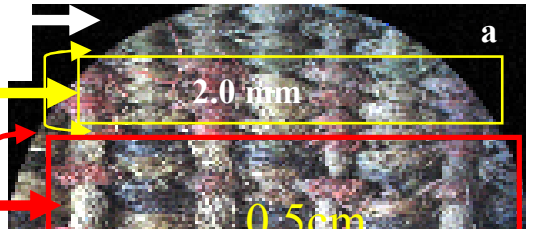

(3) Normal plain weave $1 / 1$
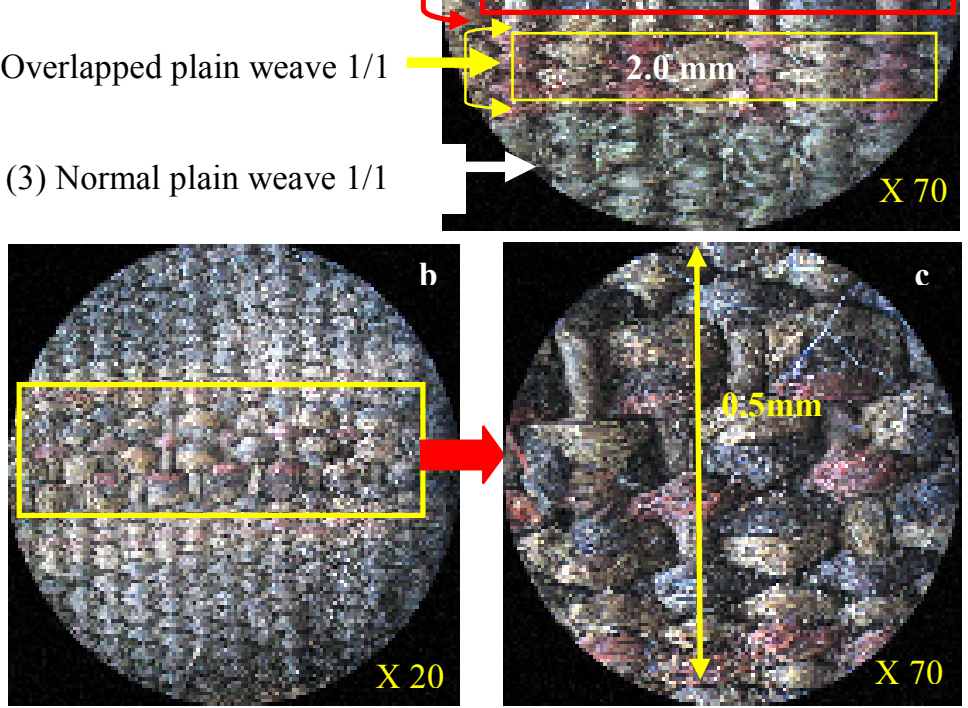

Fig. 5 microscopic images by using (SM) show the weave structures for the $1^{\text {st }}$ fragment
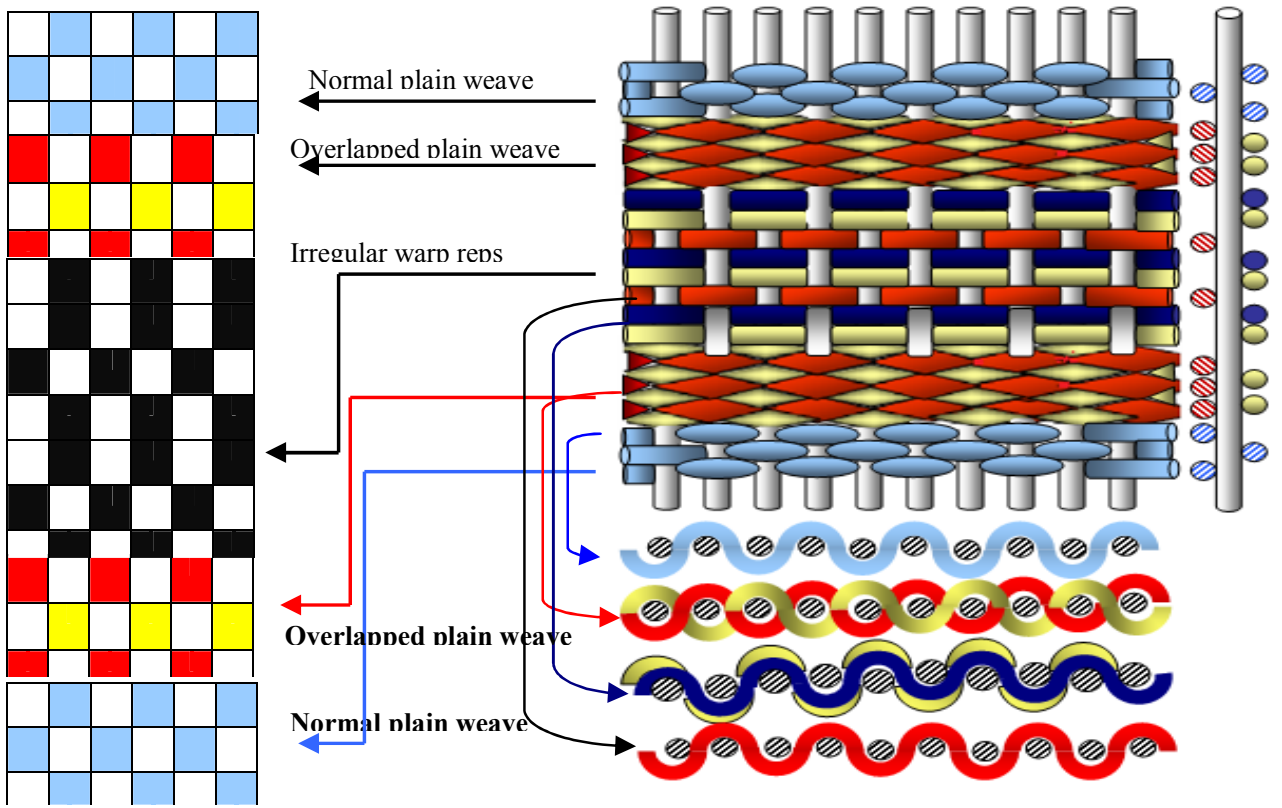

Cross-section of three techniaues of weave structure

Fig. 6 figured texture pattern show the graphical pattern, design and cross-section of weave structure techniques in the $1^{\text {st }}$ fragment

$$
-\pi-
$$




\subsubsection{The second textile fragment}

Although this object is considered one of small measure $(11.4 \times$ $12.4 \mathrm{~cm}$ ) fig. 7, it contained a lot of details whether method of the spinning yarn or the weave structure. This fragment is therefore considered one of the most important objects which indicate that it was apart of great important garment. Also, it proved that development of the textile manufacture in ancient period. This fragment consists of two techniques of weave structure; regular warp reps $2 / 2$ and irregular warp reps $2 / 3$ fig. 8 . These techniques were derived from the plain weave. If the weft of plain weaving pattern are arranged 2 at a time and put in as shown in fig. 9 (a) fine ridged is shown in direction of warp threads regularly, so this technique is called regular warp reps $2 / 2 .^{6}$ Whereas, if the weft threads are arranged 2 at a time and 3 at another time in direction of warp threads then it is called irregular warp rep 2/3, fig. 9 (b)

Fig. 7 the $2^{\text {nd }}$ fragment that was found out at the southern excavation of temple of Ramses II in Akhmeem city

Fig. 8 microscopic images by stereo microscope illustrate two techniques of weave structure; (a) regular warp reps $2 / 2$ and (b) irregular warp reps $2 / 3$
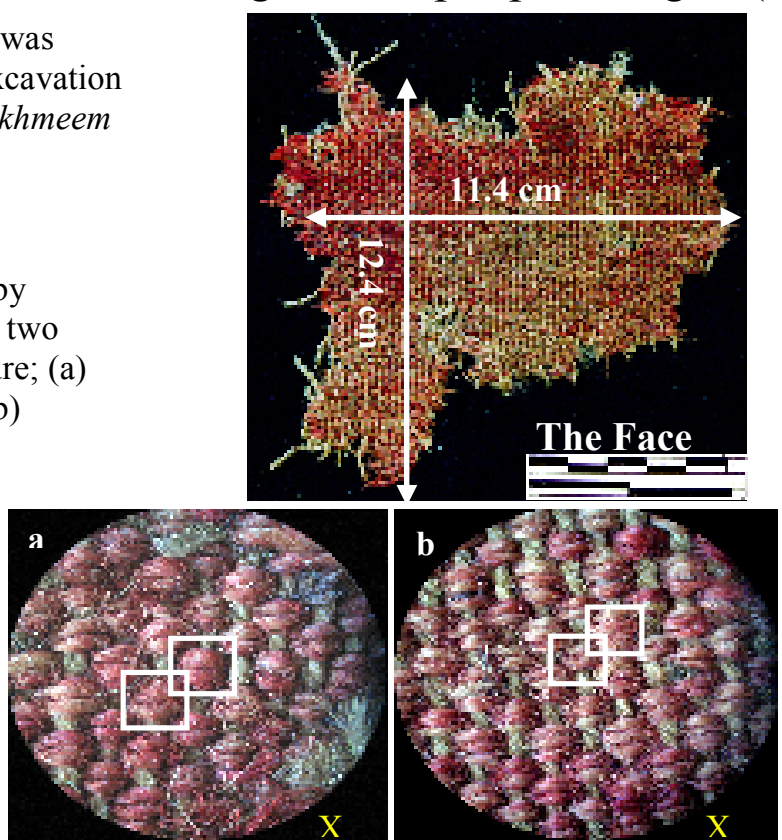

${ }^{6}$ Orazio, L., D., et al; (2000); 'Nature, origin and technology of natural fibers of textile artifacts recovered in the ancient cities around Vesuvius" Journal of Archaeological Science, http://www.idealibrary.com , p. 753 
Fig.9 figured texture pattern show two types of the weave structures found out in the $2^{\text {nd }}$ fragment; (a) regular warp reps $2 / 2$ and (b) irregular warp reps $2 / 3$ a
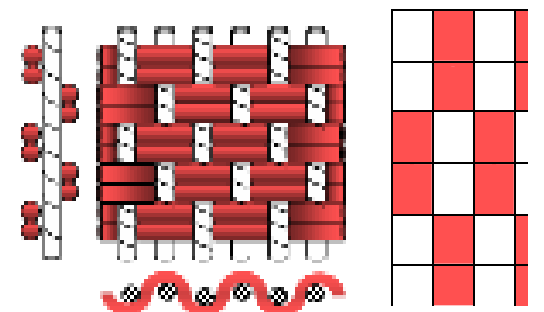

b

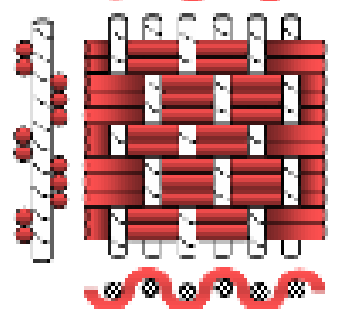

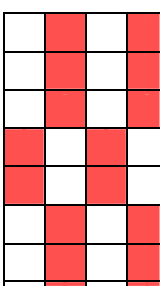

\subsubsection{The third textile fragment}

The microscopic investigation indicated that the plain weave $1 / 1$ is the dominant technique in this fragment, but there are very small regions that were ornamented by using two weft threads and the others with different color (red) were weaved with warp thread as follows; fig. 10, 11 and 12

Fig. 10 the $3^{\text {rd }}$ fragment that was found out at the northern excavation of temple of Abydos

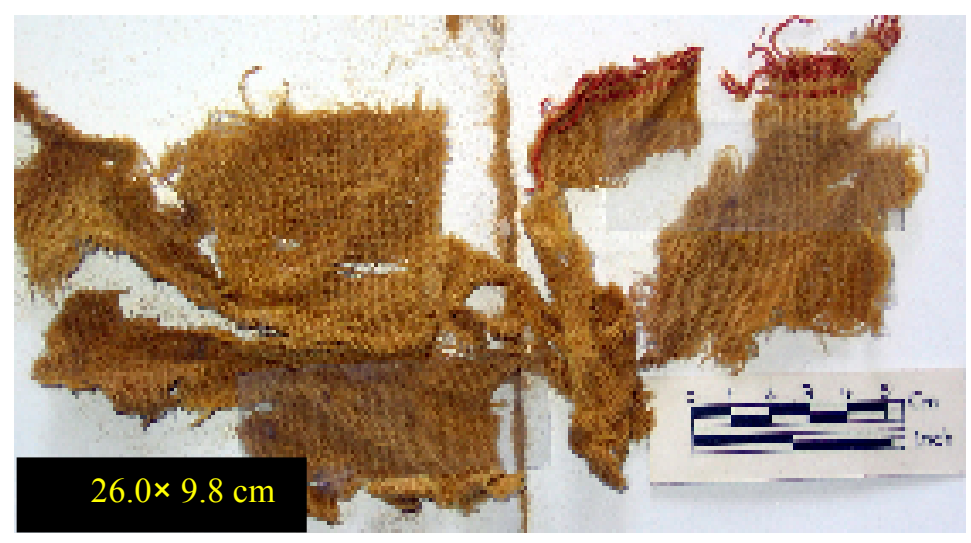

Fig. 11 microscopic images show the weave structure in the $3^{\text {rd }}$ object
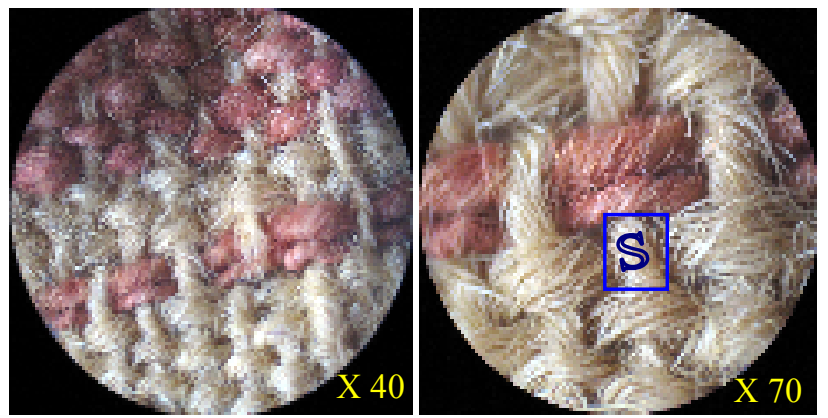


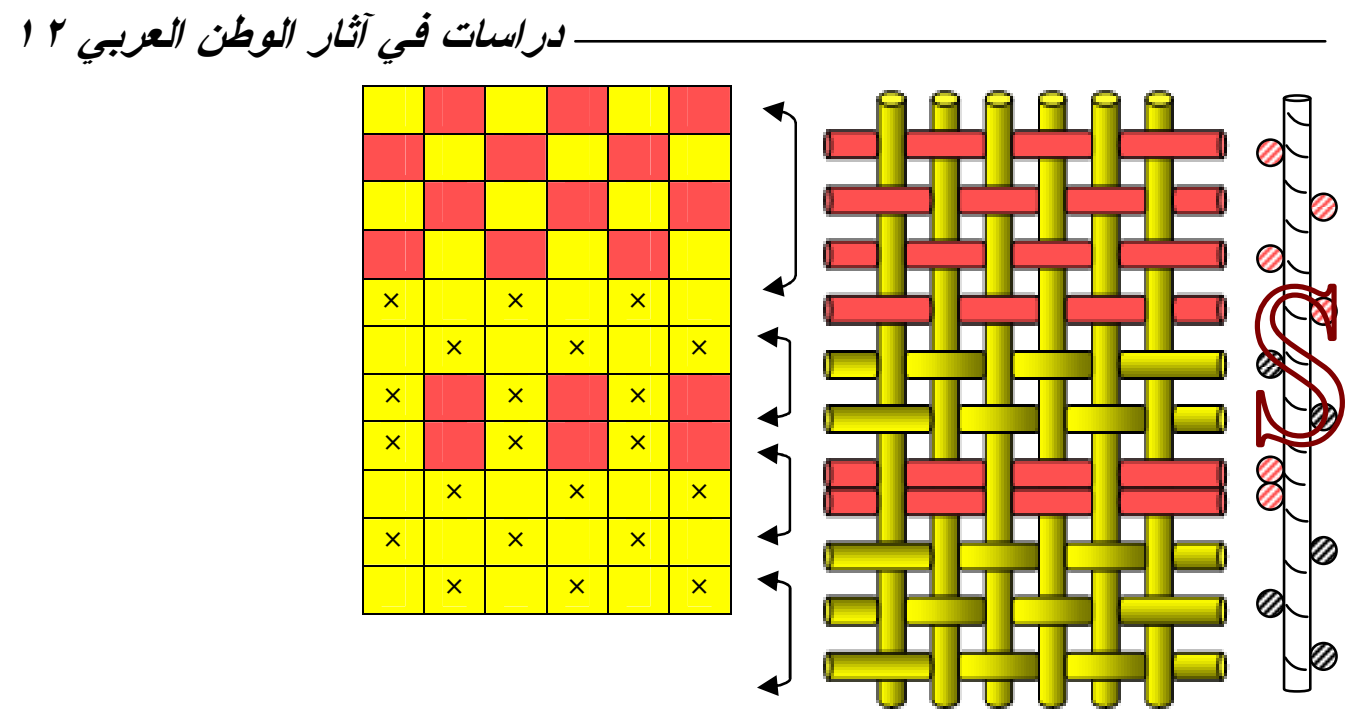

Fig. 12 figured texture pattern illustrates the main weave structure; plain cloth 1/1

\subsection{Investigation of the spun yarns}

This investigation aims to identify the thread's torsion's direction whether in ( $Z$ torsion or $S$ torsion of the yarn) and number of ply of the twisted threads whether in warp and weft for each fragment because information can be used in determining originality and manufacture's place of these fragments. As shown by the data reported in table 1, the spinning process was made both in a dextrorse sense (from left to right) ( $Z$ torsion of the yarn) and in a sinistrorse sense (from right to left) ( $\mathrm{S}$ torsion of the yarn). In particular, (S) spinning proves to be prevalently used for warp and weft threads in three fragments. On the other side, $(Z)$ spinning proves to only use for weft threads in the second fragment, fig. 13.

In this context, the microscopic investigation indicated that number of ply for threads whether in warp thread are triple, double and single ply yarn respectively, (tight yarn). As against this, number of ply of weft threads are single yarn (non-tight yarn) for each fragment, fig. 14. 


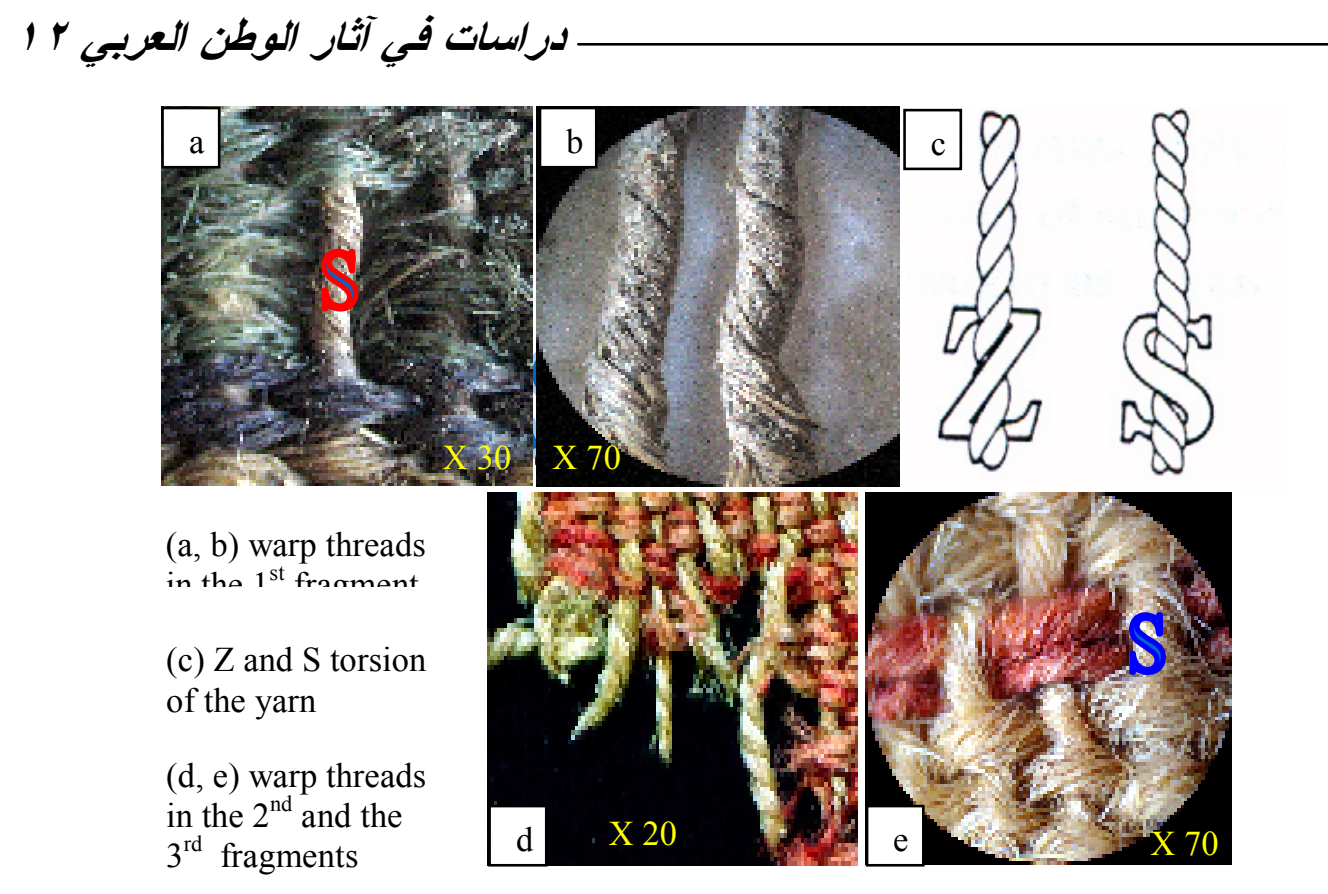

Fig.13 microscopic images and drawings show the torsion's directions of warp and weft threads for three fragments

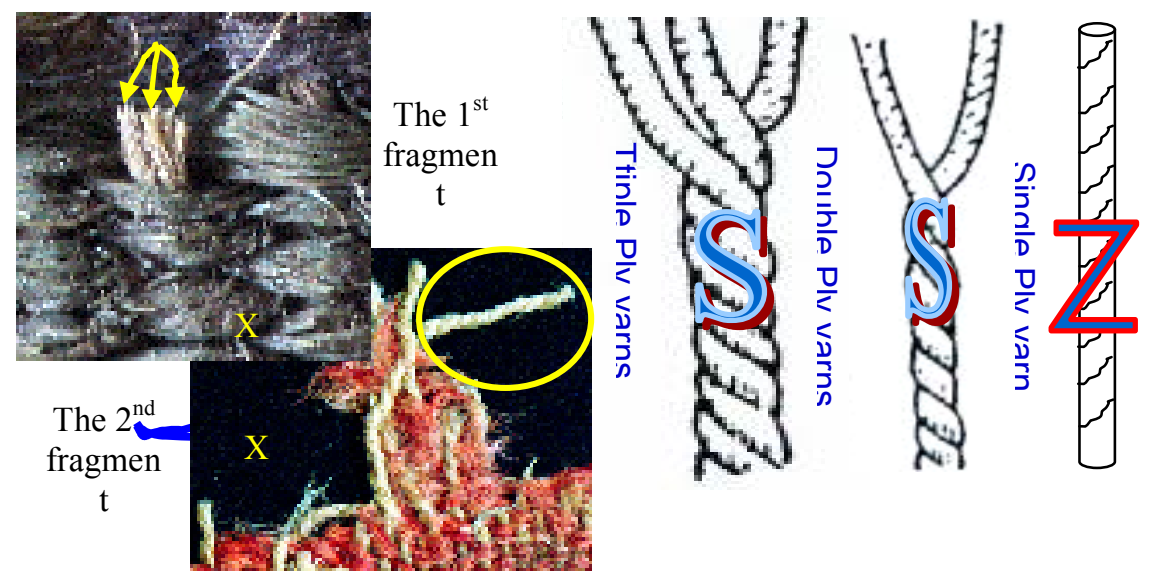

Fig. 14 microscopic images and drawings show number of ply of warp threads for

\section{Discussions and Conclusions} each fragment

Morphological investigation technique which was adequately adjusted, by Scanning Electron Microscope (SEM) allowed us to identify the nature and origin of the natural fibers composing the textile fragments. Wool fibers were recognized as natural fibers were used in three fragments whether in the warp or weft threads. 
In this context, this microscopic investigation is considered a nondestructive technique; only single fibers (a few $\mu \mathrm{m}$ in diameter) of the fiber material are required ${ }^{7}$. However, it should be noted that the epidermic layer of such fibers is composed of scales which are close one to the other and only slightly protruding, also characterized by non-indented edges (see figure 3 a, d) these morphological characteristics are distinctive of wool fibers.

Characteristic features of wool fibers such as the length of scales and diameter of wool fiber were detected; the average visible scale length of wool fibers for the first fragment ranges in length from 8$10 \mu \mathrm{m}$ for warp threads and from $5-8 \mu \mathrm{m}$ for weft threads. While the scale length of wool fibers for the second fragment ranges in length from 16-18 $\mu \mathrm{m}$ for warp threads and from 14-16 $\mu \mathrm{m}$ for weft threads, the average of diameter of wool fibers for the $1^{\text {st }}$ fragment ranges from 18-20 $\mu \mathrm{m}$ for warp threads and 16-18 $\mu \mathrm{m}$ for weft threads. While the second fragment ranges from 23-25 $\mu \mathrm{m}$ for both warp and weft. This information means that the used wool fibers are considered fine and thin fibers for the $1^{\text {st }}$ fragment and thick and coarse. The mean fiber diameter of a lot of wool is its most important single property from the technological point of view: it largely-but not entirely- determines the grade or count assigned to the lot in the usual expert assessment. So it is thought that the wool fibers in the $1^{\text {st }}$ fragment are from medium type. While the wool fibers of the $2^{\text {nd }}$ fragment are thick type. These descriptions mean that these may interpret the numerous counts of warp and weft threads in $1 \mathrm{~cm}^{2}$ ( 8 warps $\times 30$ wefts) were woven in the $1^{\text {st }}$ fragment, as a contrast, little counts of warp and weft thread in $1 \mathrm{~cm}^{2}$ (6 warps $\times 15$ wefts $)$ were woven in the $2^{\text {nd }}$ fragment. Moreover, it thought that these fibers may be original textiles were made of Egyptian wool fibers.

The microscopic investigation technique (Stereo microscope) was used to determine the weave structures for each fragment, a plain

\footnotetext{
${ }^{7}$ Müller, M. et al; (2004) op cit; p. 1673
} 
weave technique and its derivates such as reps technique whether regular or irregular warp reps was used in three fragments. These information prove that three fragment approximately were woven in one period and place. This textile type is considered one of the most important techniques that were used in Egypt, so it thought that these fragment were part of clothes were woven in Egypt.

For each fragment studied, the type of spinning and weave used to obtain the textile was also determined. The spinning process of the fibers composing the fragments studied was conducted both in a dextrose sense with $(Z)$ thread torsion, and in a sinistrorse sense with (S) thread torsion. The (S) spinning proved to be prevalently used for the manufacturing of three fragments, especially in the warp threads, while the $(\mathrm{Z})$ spinning was only used for the weft threads in the $2^{\text {nd }}$ fragment. According to many previous literature studies (pfister $1934^{8}$, Lamm $1936^{9}$ and Künhnel \&Lousia $1952^{10}$ ) that the most of spun yarns (which were made in Egypt) were twisted from right to left ('S' thread torsion) $)^{11}$. Therefore, it could be suggested that these fragments were spun and made in Egypt.

Finally, we must be interested in every textile fragment which could be found out in the excavations because these objects can lead us to understand origin and technology of archaeological textiles (type of spinning and weave). In addition to study information relate to the archaeological questions surrounding history of these objects and

\section{Acknowledgements}

The author wishes to thank my colleagues in the superior council of Archaeology for supplying me with textile fragments which were studied in this paper. Also, I would like to thank all colleagues in Scanning Electron Microscopy center in Sohag University for their good efforts including investigation and analysis processes of the textile samples.

${ }^{8}$ Pfister, R. (1934); " Textiles de Palmyra (Revue de Arts Asiatiques) Vol. VIII, paris.

${ }^{9}$ Lamm, (1936); "Cotton in Medieaval textile of the Near East. Paris.

${ }^{10}$ Kühnel and Lousia (1952) 'Catalogue of Dated Tiraz- Washington Museum'

${ }^{11}$ Maher, S. (1977); " Islamic Textile" Cairo, pp: 15-16 